\title{
Experimental investigations of flat plate heat pipes with screen meshes or grooves covered with screen meshes as capillary structure
}

\author{
Frédéric Lefèvre*, Jean-Baptiste Conrardy, Martin Raynaud ${ }^{+}$, Jocelyn Bonjour \\ Université de Lyon, CNRS \\ INSA-Lyon, CETHIL, UMR5008, F-69621, Villeurbanne, France \\ Université Lyon 1, F-69622, France \\ ${ }^{+}$Thales Communications, Thales, 92701 Colombes, France \\ *(corresponding author: frederic.lefevre@insa-lyon.fr)
}

\begin{abstract}
Experimental investigations of two different flat plate heat pipes (FPHP) are presented. The capillary structure is made of one or two screen mesh layers for the first FPHP and screen mesh covered grooves for the second FPHP. The heat pipes, filled with methanol, were tested in different configurations i.e. with various locations of heat sinks and heat sources, numbers and natures of the heat sinks and orientation. Water heat exchangers were first used as heat sinks to estimate the performance of the capillary structures. Experiments were also performed with aluminium radiator cooled by natural convection of air in order to show the performance of the FPHP in experimental conditions representing a practical case, typically the cooling of electronic equipments. The results show the interest of this solution for the proposed application. The method chosen to assemble this FPHP prototype with meshes is very simple and cheap. On the contrary, the performance of the heat pipe obtained with the association of grooves and meshes is not as high as one could expect. Indeed, if this capillary structure allows working in tilted unfavourable position, which is not possible with grooved heat pipe, a clear nucleate boiling limitation is observed for rather small heat fluxes.
\end{abstract}

Keywords: flat plate heat pipe; screen mesh layers; grooves; experimental study; electronic cooling

\section{Introduction}

The interest in the use of heat pipes for thermal management is recognized in many industrial applications. For example the thermal management of electronic equipments has become an important issue because of increasing power levels along with the miniaturization of the devices. With the advent of denser device packaging and faster intrinsic speeds, cost, reliability and size have been improved, but it requires new cooling solutions often based on liquid/vapor phase change systems. As a first approach, the thermal performance of a heat pipe can be characterized by both its overall thermal resistance and its maximum power in horizontal and vertical positions. These characteristics depend mainly on the capillary structure, which is usually made of grooves, meshes, sintered powder or a combination of them. In many applications, heat pipes are circular and are used to transport heat from one heat source to one heat sink, which can be any cooling system. Planar heat pipes, also called flat plate heat pipes have the same components, but offer a wide cross- 
section, which allows reducing their thickness without reducing their thermal performance. Furthermore, several heat sources can be located on them, which is interesting to cool electronic cards, with many electronic components.

Lots of experimental and theoretical works have been published on flat plate heat pipes with rectangular grooves or also on micro heat pipes arrays in both steady [1-5] and transient states [6,7]. Numerical models of such capillary structures are generally based on conservation equations and on Young-Laplace's law, which links the shape of the liquid-vapour interface to the hydrodynamic parameters [1-5]. Thus, the shape of the liquid-vapour interface is calculated at each point of the grooves. In addition, recent experimental works presented accurate measurements of the meniscus in grooved FPHP using confocal microscopy [8-10]. Thus, numerical models can be validated and a detailed description of the physical mechanisms involved in a grooved heat pipe is now available.

In [11], nucleate boiling was observed at the evaporator of a grooved FPHP for relatively small heat fluxes $\left(\sim 3 \mathrm{~W} / \mathrm{cm}^{2}\right)$. The authors showed that the phenomenon of nucleate boiling improves the thermal performance of the flat heat pipe, and they emphasized that the presence of bubbles does not prevent the proper circulation of the fluid, contrary to what is generally stated in the literature and referred to as "boiling limit". Dryout of the evaporator was observed for heat fluxes much higher than the heat flux of onset of nucleate boiling. In [12], Lips et al. showed, using confocal microscopy measurements that this dryout was not due to the boiling phenomenon but that it was a classical capillary limit.

In more complex capillary structures such as meshes or sintered powder, it is difficult to calculate the exact location of both the liquid and the vapour inside the system and also difficult to determine it experimentally. Theoretical model are based on Darcy's law, with the permeability and the equivalent thermal conductivity of the capillary structure as main parameters. Experimentally, temperature measurements are used to estimate the maximum power and the overall thermal resistance. In addition, some papers present transparent heat pipes to visualize phenomena occurring in working conditions. Nevertheless, a fine description of the liquid-vapour interface is not yet available.

Kempers et al. [13] tested the effect of the number of screen mesh layers (wire diameter $109 \mu \mathrm{m}$ ) and fluid filling on a circular heat pipe of length $177.8 \mathrm{~mm}$ and inner diameter $6.22 \mathrm{~mm}$. As expected, the maximum heat transfer increases with the number of meshes, but the increase in thermal resistance due to the increase of mesh number is found to be significantly lower than that predicted by conduction-based models. These authors showed that decreasing the amount of 
working fluid decreases the effective thermal conductivity but also the maximum power. In another study [14], Kempers et al. showed that heat transfer in the condenser is reasonably equal to that calculated by conduction models, while at the evaporator, a threshold due to nucleate boiling changes significantly heat transfer coefficients. The work of Kempers et al. [14] confirms observations made by Lips et al. [11] in grooved capillary structures: boiling activity in the screen wick was in fact observed to augment performance, not to limit it.

Wong et al. [15] made visualisations of the evaporation/boiling process in transparent circular heat pipes of length $150 \mathrm{~mm}$ and inner diameter $5 \mathrm{~mm}$. Two layers of screen mesh are placed in the pipe. Two different meshes were tested (wire diameters $114 \mu \mathrm{m}$ and wire diameters $55 \mu \mathrm{m}$ ). They observed nucleate boiling for heat fluxes higher than $15 \mathrm{~W} / \mathrm{cm}^{2}$ at the evaporator. In two other articles, Wong et al. [16] and Liou et al. [17] reported visualisations in transparent flat plate heat pipes, made of sintered screen meshes (same characteristics as in [15]) or sintered copper powder. In both works, they did not observe nucleate boiling even for high heat fluxes $\left(60 \mathrm{~W} / \mathrm{cm}^{2}\right)$. In these three works [15-17], observations of wetted area or nucleation process were made by a CCD camera. Obviously, this technique does not permit to measure the exact location of the liquidvapour interface but provides some useful qualitative information.

Li et al. [18-19] studied the evaporation/boiling phenomena inside sintered screen meshes (wire diameters $56 \mu \mathrm{m}, 114 \mu \mathrm{m}$ and $191 \mu \mathrm{m})$. Experimental results showed that while the evaporation/boiling heat transfer coefficient is not affected by the thickness of the capillary structure, the critical heat flux increases proportionally to this thickness. Furthermore, the evaporation/boiling heat transfer coefficient decreases with the wire diameter, but is not strongly dependant on the porosity. On the contrary, the authors showed that the critical heat flux increases with both the wire diameter and the porosity. In [20], Li et al. presented a detailed and comprehensive literature review on the effective thermal conductivity of screen meshes. They also developed an analytical model, in which the number of meshes, the wire diameter and the compression factor are preponderant. The model was compared to experimental data.

Do et al. [21] investigated the thermal performance of screen mesh wick heat pipes using waterbased $\mathrm{Al}_{2} \mathrm{O}_{3}$ nanofluids. A significant decrease of the thermal resistance was observed. The authors showed that this enhancement of the thermal performance is due to the thin porous coating layer formed by nanoparticules at the wick structure, a phenomenon that was described in details for pool boiling experiments by Stutz et al. [22]. 
This article reports experiments performed with two flat plate heat pipes with rather large dimensions. These heat pipes essentially differ from their capillary structure, which is made of screen meshes for the first FPHP and of screen meshes associated with rectangular grooves for the second FPHP. The meshes are not sintered like in [18-19], but plated against the wall by means of a coarse screen mesh, as recommended in [23]. This technological solution makes it very easy to assemble. The heat pipes have been tested in different configurations, i.e. one or two layers of mesh were used, several locations of the heat $\operatorname{sink}(\mathrm{s})$ and heat source were tested with various numbers and natures of the heat sinks and for different orientations.

\section{Experimental set-up}

\subsection{FPHP made of one or two screen mesh layers}

The first flat plate heat pipe under investigation (called heat pipe $\mathrm{n}^{\circ} 1$ in the following) is shown in figure 1. It is made of one copper plate of thickness $1.5 \mathrm{~mm}$ and surface $267 \times 115 \mathrm{~mm}^{2}$. The FPHP is hermetically sealed on its upper face with a transparent plate, which allows observations inside the system. A Viton flat ring of thickness $2 \mathrm{~mm}$ is placed between the copper and the transparent plates to ensure tightness. The capillary structure, of dimensions $230 \times 90 \mathrm{~mm}^{2}$, is made of 1 or 2 CuSn 325 square screen mesh layers (figure 2). The capillary screen meshes are plated against the copper plate by means of a coarse screen mesh, which creates the vapor space. Eight micro grooves are etched at the back of the copper plate in order to embed $100 \mu \mathrm{m}$ diameter thermocouples (uncertainty lower than $0.2 \mathrm{~K}$ ), using silver lacquer in order to reduce the contact resistance (figure 1). Their voltage is recorded by a Keithley 2700 multimeter.

The heat source is a thick resistor film of dimensions $55.1 \times 96.5 \mathrm{~mm}^{2}$ and resistance $90.6 \Omega$, which is supplied by a stabilised DC power supply. It is plated against the copper wall by means of high conductive thermal grease. Electric power is obtained by measuring the voltage drop across the heating resistor and the intensity, by means of a calibrated resistance. Thus, the uncertainty for the heating power is negligible. Two different heat sinks are tested:

- Two aluminium radiators $\left(140 \times 170 \mathrm{~mm}^{2}\right)$ cooled by natural convection of air at ambient temperature. Two thermal wedge locks are screwed on each radiator to maintain the FPHP by means of two small fins located on each side of the FPHP (figure 1). The contact area between the thermal wedge lock and the heat pipe is equal to twice $105 \times$ $5 \mathrm{~mm}^{2}$. These radiators are used to simulate a practical application, namely the cooling 
of electronic cards, which are most of the time located inside a metallic rack. The rack is used as a radiator to dissipate heat to the ambient air. The idea is to insert the FPHP into the metallic box exactly like an electronic card, using thermal wedge locks.

- One or two water heat exchangers of heat transfer area $30 \times 90 \mathrm{~mm}^{2}$. The water flow rate is constant and the inlet temperature is controlled by means of a thermostatic bath in order to have a constant temperature for all experiments. It is useful for the determination of the FPHP characteristics. Heat sinks are plated against the copper wall using high conductive thermal grease.

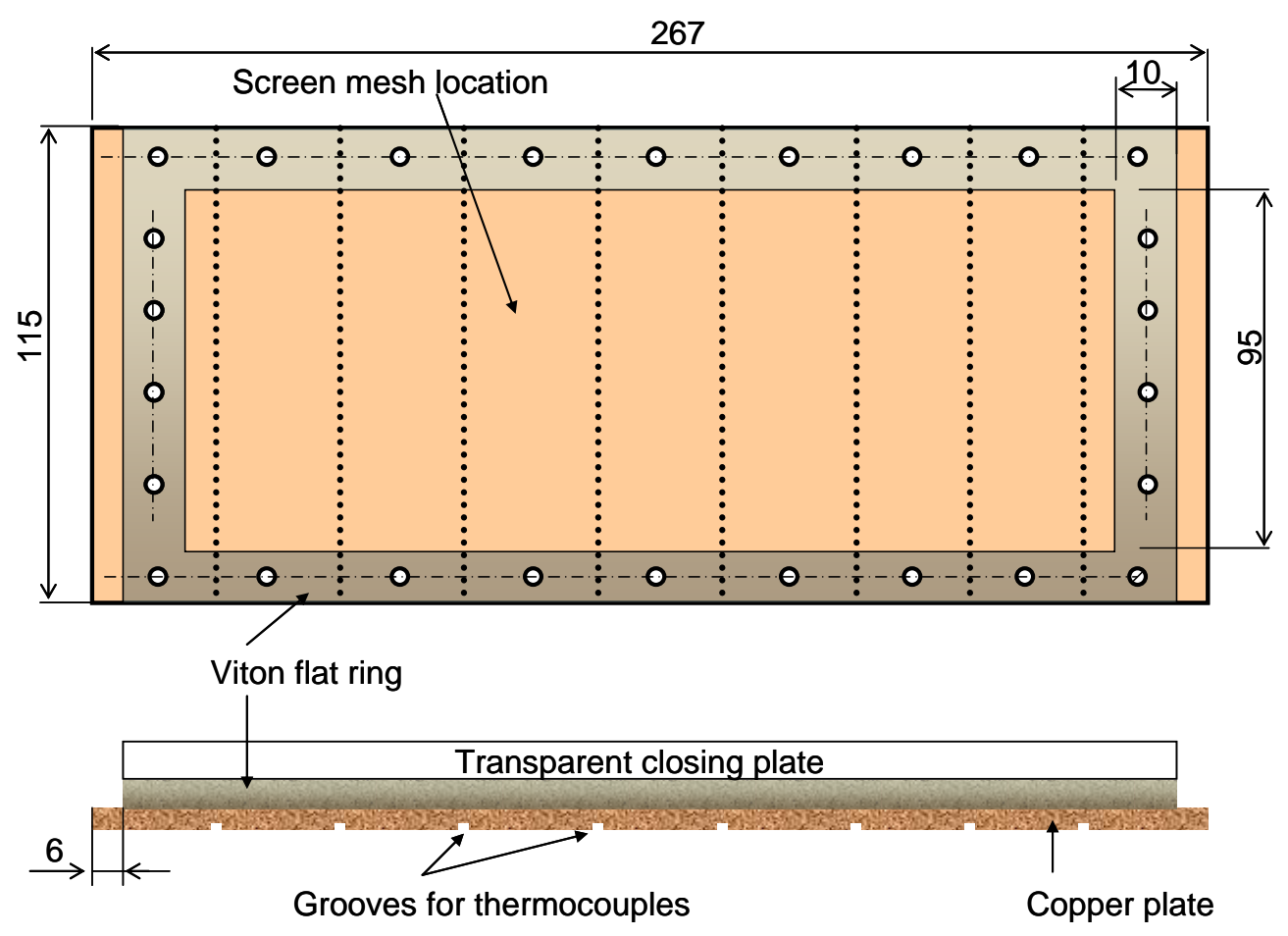

Figure 1: Schematic of the screen mesh FPHP 

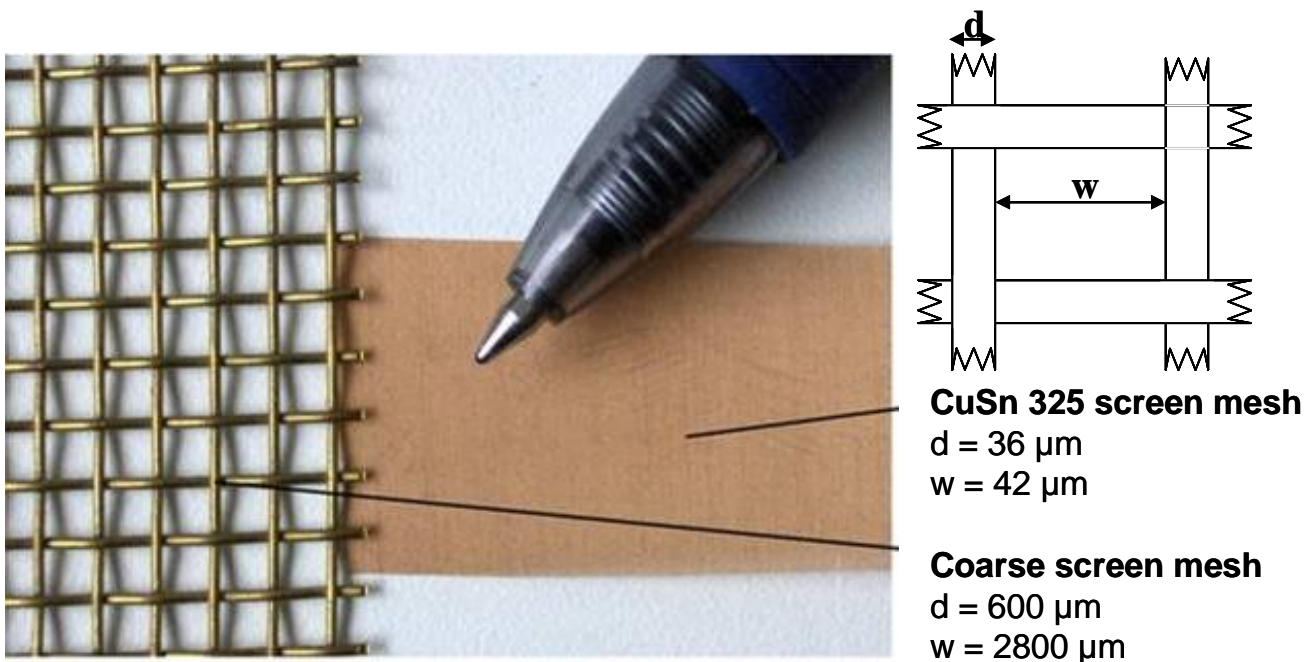

Coarse screen mesh

$\mathrm{d}=600 \mu \mathrm{m}$

$\mathrm{w}=2800 \mu \mathrm{m}$

Figure 2: Coarse and fine screen meshes

\subsection{FPHP made of grooves covered by two screen mesh layers}

The second FPHP under investigation (figure 3, heat pipe $\mathrm{n}^{\circ} 2$ ) is made of 109 longitudinal microgrooves, covered by two screen mesh layers. The grooves are machined in a copper plate. They are similar to those of another FPHP already described in previous articles [1,2]. Each groove has a rectangular cross-section of height and width equals to $380 \mu \mathrm{m}$ and $400 \mu \mathrm{m}$, respectively. The distance between two grooves is equal to $400 \mu \mathrm{m}$. The area of the grooved surface is equal to $230 \times$ $90 \mathrm{~mm}^{2}$. The vapour space, machined inside the copper plate, has a height of $1.6 \mathrm{~mm}$. The wall thickness under the grooves is equal to $2 \mathrm{~mm}$. The FPHP is hermetically sealed on its upper face with a transparent plate and a Nitril o-ring to ensure tightness. If good thermal performance was obtained with this heat pipe in horizontal position (or even in vertical favourable position) [1,2], it was not able to work in tilted position because capillary pressure induced by the grooved capillary structure was too small to overcome hydrostatic pressure drop in vertical position. This justifies the adjunction of the two layers of screen mesh to the original groove FPHP: in order to overcome this limit, these screen meshes were plated against the grooves, similarly to the method used in section 2.1 , in order to increase the capillary pressure gradient while preserving the high permeability of the grooves. 


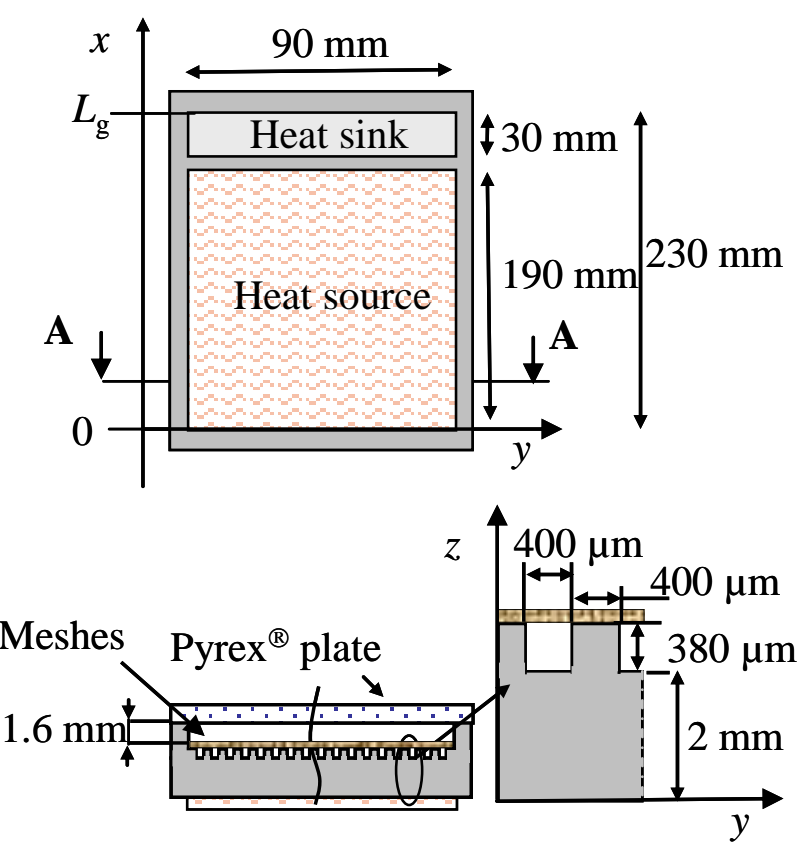

Cross-section A-A

Figure 3: Schematic of the experimental bench

The heat source is plated on the copper wall. It is a thick resistor film of area $190 \times 90 \mathrm{~mm}^{2}$. This resistor of $2.1 \Omega$ is supplied by a DC power supply. The heat sink is a water heat exchanger whose characteristics are the same as the heat exchangers presented in section 2.1. The heat source and the heat sink are separated by an adiabatic area of length equal to $10 \mathrm{~mm}$. They are both plated against the copper wall using high conductive thermal grease. It has to be noted that the heat source area is much larger than those of the heat sink and of the adiabatic surface. The reason is the initial foreseen application of that FPHP that was the cooling of proton exchange membrane fuel cells. The same characteristics have been retained for this study to allow comparison with previous results [1]. Seven thermistors (uncertainty lower than $0.2 \mathrm{~K}$ ) are located along the wall and the value of their resistance is recorded by a Keithley 2700 multimeter.

\section{Experimental results}

Both FPHPs are thermally insulated during thermal tests with $5 \mathrm{~cm}$ thick fiberglass insulation. As a result, considering a heat transfer coefficient of $10 \mathrm{~W} / \mathrm{m}^{2} \mathrm{~K}$ between the fiberglass insulation and the ambient air and a maximum temperature difference of $40 \mathrm{~K}$ between the heater and the ambient air, the heat losses over the heater are lower than $0.5 \mathrm{~W}$ for the FPHP $\mathrm{n}^{\circ} 1$ and lower than $0.15 \mathrm{~W}$ for the FPHP n ${ }^{\circ} 2$. 
Both FPHP are first degassed and filled. In order to promote surface wetting, the copper plate is first cleaned. The FPHP and the working fluid are degassed carefully to eliminate the noncondensable gases. The method of evacuating the non-condensable gases from the working fluid is based on the fluid solidification under vacuum. The fluid contained in a heated vessel vaporizes, releases non-condensable gases and solidifies in a second vessel immersed into liquid nitrogen. The non-condensable gases are evacuated by vacuum pumps. The FPHP is degassed by heating during vacuum pumping at $10^{-5}$ mbar.

\subsection{FPHP made of one or two screen mesh layers}

The heat pipe $n^{\circ} 1$, filled with methanol, has been tested in different configurations. The optimal filling ratio (i.e. the filling ratio corresponding to the smallest thermal resistance of the FPHP, which is measured as the ratio of height of liquid to height of FPHP in vertical position) is around $20 \%$ when the FPHP is horizontal. It is found to be slightly lower when the heat pipe is tilted.

\subsubsection{Experiments with one heat source and one heat sink located on both extremities of the heat pipe}

In this part, the FPHP $n^{\circ} 1$ is tested with one heat source and one heat sink, each located at one extremity of the heat pipe. This is the worst configuration because liquid and vapour have to flow along the whole length of the heat pipe, which generates high pressure drops. Nevertheless, this configuration is interesting to evaluate the heat transfer capability of the heat pipe.

The working temperature is set to around $30{ }^{\circ} \mathrm{C}$. Figure 4 presents the temperature profile along the heat pipe having only one screen mesh for 5 powers $(\mathrm{Q}=7,3 \mathrm{~W} ; \mathrm{Q}=11,4 \mathrm{~W} ; \mathrm{Q}=15,9 \mathrm{~W} ; \mathrm{Q}=$ $18,2 \mathrm{~W} ; \mathrm{Q}=19,4 \mathrm{~W}$ ) in horizontal position. Locations of the heat sink and the heat source are symbolized by two rectangles on the $\mathrm{x}$ axis. A proper working of the heat pipe is observed for powers lower than $18 \mathrm{~W}$. Beyond this value, a sudden dryout is observed, which degrades the thermal performance: the capillary limit is reached.

Figure 5a presents the maximal temperature difference (i.e. the difference between the maximum evaporator and minimum condenser temperatures) vs. power for the FPHP having one or two screen mesh layer(s), in horizontal orientation. In order to have a comparison criterion, the maximum temperature difference obtained by heat conduction through the copper plate that forms the body of 
the heat pipe only is presented. This last curve has been obtained using experimental results performed with a power of $10 \mathrm{~W}$, which were linearly extrapolated for the other powers. With one or two screen meshes, the maximum temperature measured with the FPHP is much smaller than that with the copper plate of thickness $1.5 \mathrm{~mm}$. The temperature field obtained for the copper plate has been compared to a heat conduction model with a thermal conductivity of copper equal to $400 \mathrm{Wm}^{-}$ ${ }^{1} \mathrm{~K}^{-1}$. The comparison shows that heat losses of the system are lower than $10 \%$.

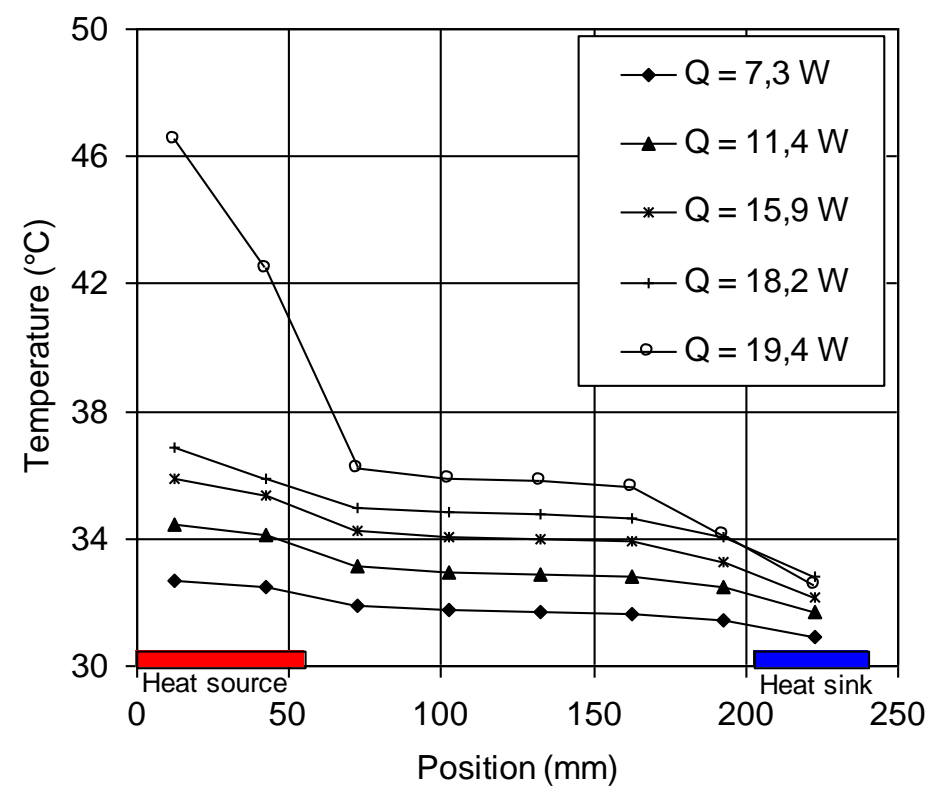

Figure 4: Temperature profile along the heat pipe with one screen mesh layer in horizontal position

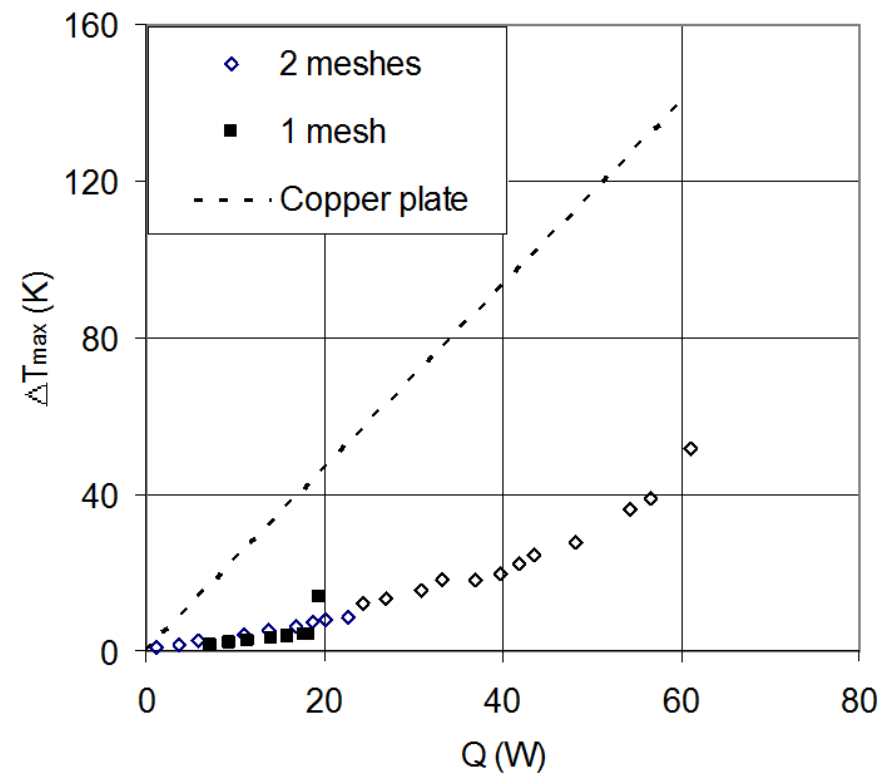

Figure 5a: Maximum temperature difference vs. power in horizontal position 
Figure $5 \mathrm{~b}$ presents the same results, but the $y$ scale is expanded 4 times. A linear behaviour is observed until a threshold power for which the maximum temperature difference increases. This threshold is relatively similar with one screen mesh $(\sim 18 \mathrm{~W})$ and 2 screen mesh layers $(\sim 22 \mathrm{~W})$. However the transition is abrupt with one mesh, whereas it is smoother with two meshes. For the case with one mesh, the threshold undoubtedly corresponds to the capillary limit. For the 2 meshes case, a so smooth variation implies that evaporation still occurs at the evaporator. There is probably a narrow dryout between the mesh and the copper plate, but liquid is still drained to the evaporator by the meshes. Furthermore, a linear behaviour is also observed for increasing powers between 22 $\mathrm{W}$ and $40 \mathrm{~W}$. Beyond $40 \mathrm{~W}$, this linear tendency is not observed any longer. These results show that the liquid film shapes inside such a capillary structure is complex and still needs to be understood. In the linear part of the curve, the thermal resistance of the heat pipe, defined as the maximum temperature difference divided by the power, is around $0.23 \mathrm{~K} / \mathrm{W}$ for one screen mesh layer, 0.38 $\mathrm{K} / \mathrm{W}$ for 2 screen mesh layers before the first threshold and $0.5 \mathrm{~K} / \mathrm{W}$ beyond it. In comparison, the thermal resistance of the copper plate is equal to $2.3 \mathrm{~K} / \mathrm{W}$. In other words, a copper plate with the same thermal performance as the heat pipe with one mesh should be $15 \mathrm{~mm}$ thick.

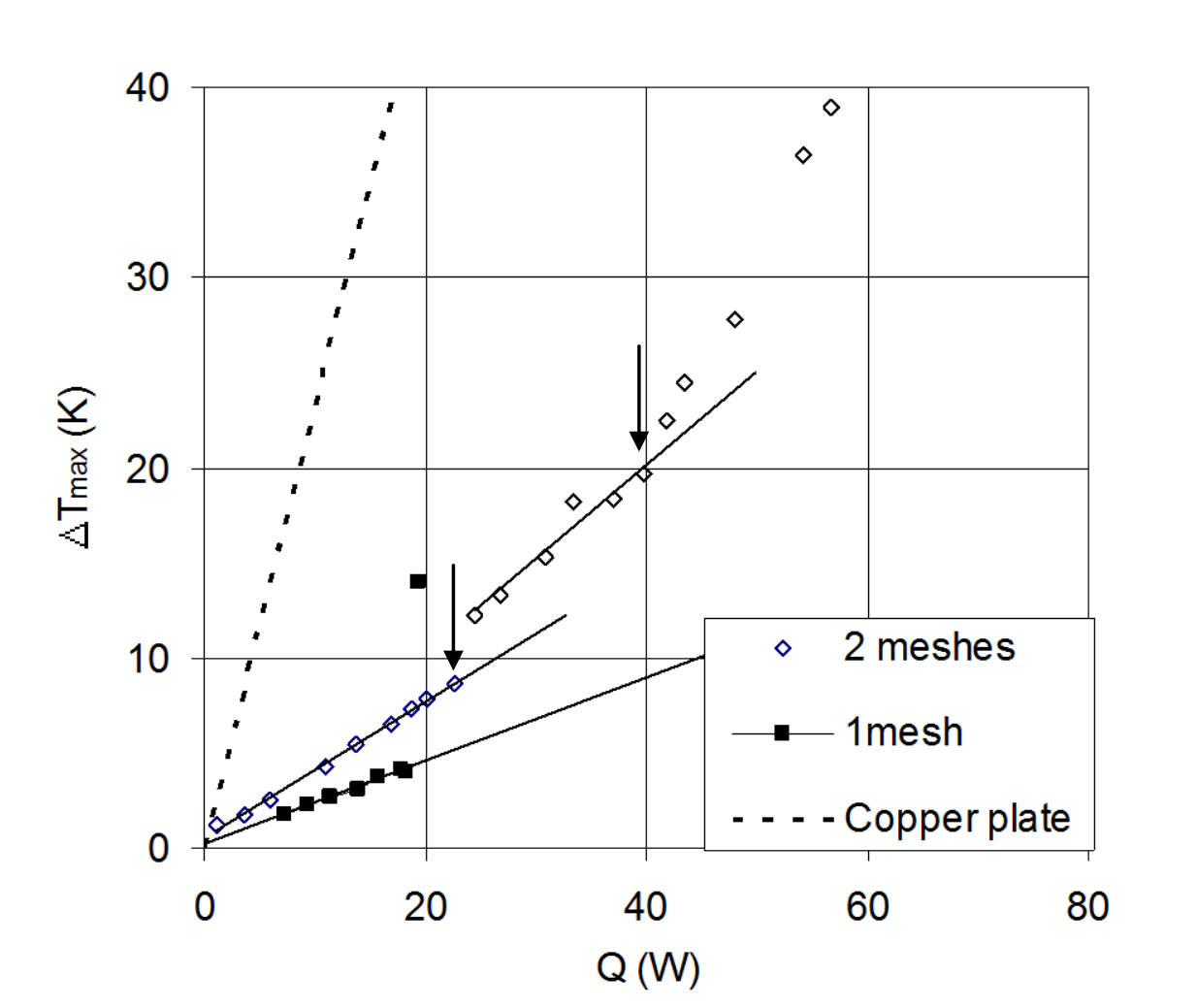

Figure 5b: Zoom of figure 5a with linear fitted curves

Figure 6 presents the maximum temperature difference along the heat pipe in several experimental conditions (filling ratio, tilt angle, number of meshes) for a constant power of $10.2 \mathrm{~W}$. The best thermal performance (dash symbols) is obtained for the heat pipe with one screen mesh layer in 
horizontal position. The other symbols are results obtained with 2 meshes. Indeed, when the heat pipe with one screen mesh layer is inclined, poor thermal performance is obtained. Square and circle symbols are the temperature fields in horizontal position for a filling ratio of $20 \%(\mathrm{~h}=4 \mathrm{~cm})$ and $10 \%(\mathrm{~h}=2 \mathrm{~cm})$ respectively. The other symbols correspond to increasing tilt angles $\left(0^{\circ}, 10^{\circ}\right.$, $25^{\circ}, 35^{\circ}$ and $45^{\circ}$ ), the heat source being above the heat sink. When the heat pipe is inclined, the best thermal performance is obtained for a filling ratio smaller $(10 \%)$ than in horizontal orientation (20\%), which is due to the excess of liquid at the condenser. The temperature field is rather homogeneous in the condenser and the adiabatic area, but it becomes less homogeneous at the evaporator when the tilt angle increases. However, in all the cases, temperature levels are considerably smaller than what they would be for heat conduction in a copper plate (line and star symbols). It has to be noted that experimental results in vertical position are not presented. Indeed, in all the cases, the maximum capillary pressure of the screen mesh layers is not sufficient to overcome the hydrostatic pressure.

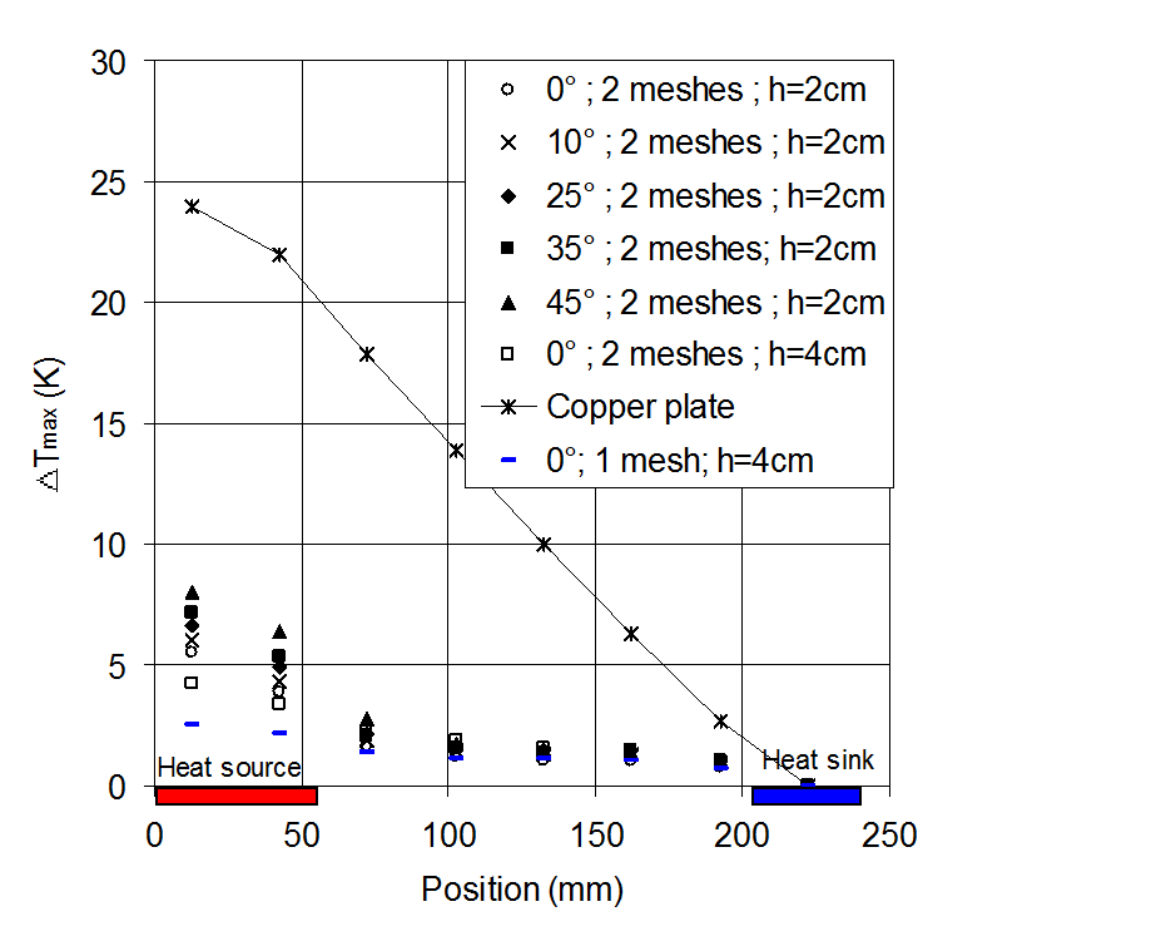

Figure 6: Temperature profile along the heat pipe $\mathrm{n}^{\circ} 1$ for a power of $10.2 \mathrm{~W}$ with a reference temperature of $0^{\circ}$ at the condenser

\subsubsection{Experiments with one heat source and two heat sinks}

In this part, we present temperature fields measured with two heat sinks at each extremity of the heat pipe $n^{\circ} 1$. This configuration corresponds to the foreseen application. The FPHP is supposed to 
be inserted in a metallic rack or chassis, used as a radiator to dissipate heat from the electronic components. The metallic rack can be used in very harsh conditions (dusty environment and high temperature levels). Thus, it is not possible to cool it directly from the inside, since it has to be tightly closed in working conditions. As a result, the heat generated by electronic components has to be transported from the inner of the rack to its external surface, where it is removed by both natural convection and radiation. A conductive plate in aluminium is used for that purpose but its thickness is important. The aim of the study is thus to replace this conductive plate by a FPHP.

For the laboratory tests of the FPHP, a single heat source is located in the middle of the FPHP. In real conditions, several electronic components would be located on the FPHP. The capillary structure is made of 2 mesh screen layers.

Figure 7 presents temperature profiles in horizontal orientations with two types of heat sinks: two water heat exchangers cooled by a thermostatic bath at a temperature close to $20^{\circ} \mathrm{C}$ or two aluminum radiators cooled by natural convection with air at ambient temperature. The thermal load is equal to $15 \mathrm{~W}$. The overall shapes of temperature fields are very similar for these two cases. The only difference is the mean temperature level, which is close to the heat sink temperature for water heat exchangers and $30^{\circ} \mathrm{C}$ higher for air radiators. This difference is due to the nature of the heat sinks and not to the FPHP: the thermal resistance of air radiators is much higher than that of water heat exchangers. As a consequence, the heat exchangers impose their temperature at the condenser. However, this comparison underlines that the nature of the heat sink does not change the FPHP behaviour. The next remaining results were obtained with water heat exchangers, which were preferred for practical reasons for that experimental campaign since steady states were obtained very quickly. Of course, water heat exchangers will not be used in the foreseen application; otherwise, the use of a heat pipe would not be necessary. 


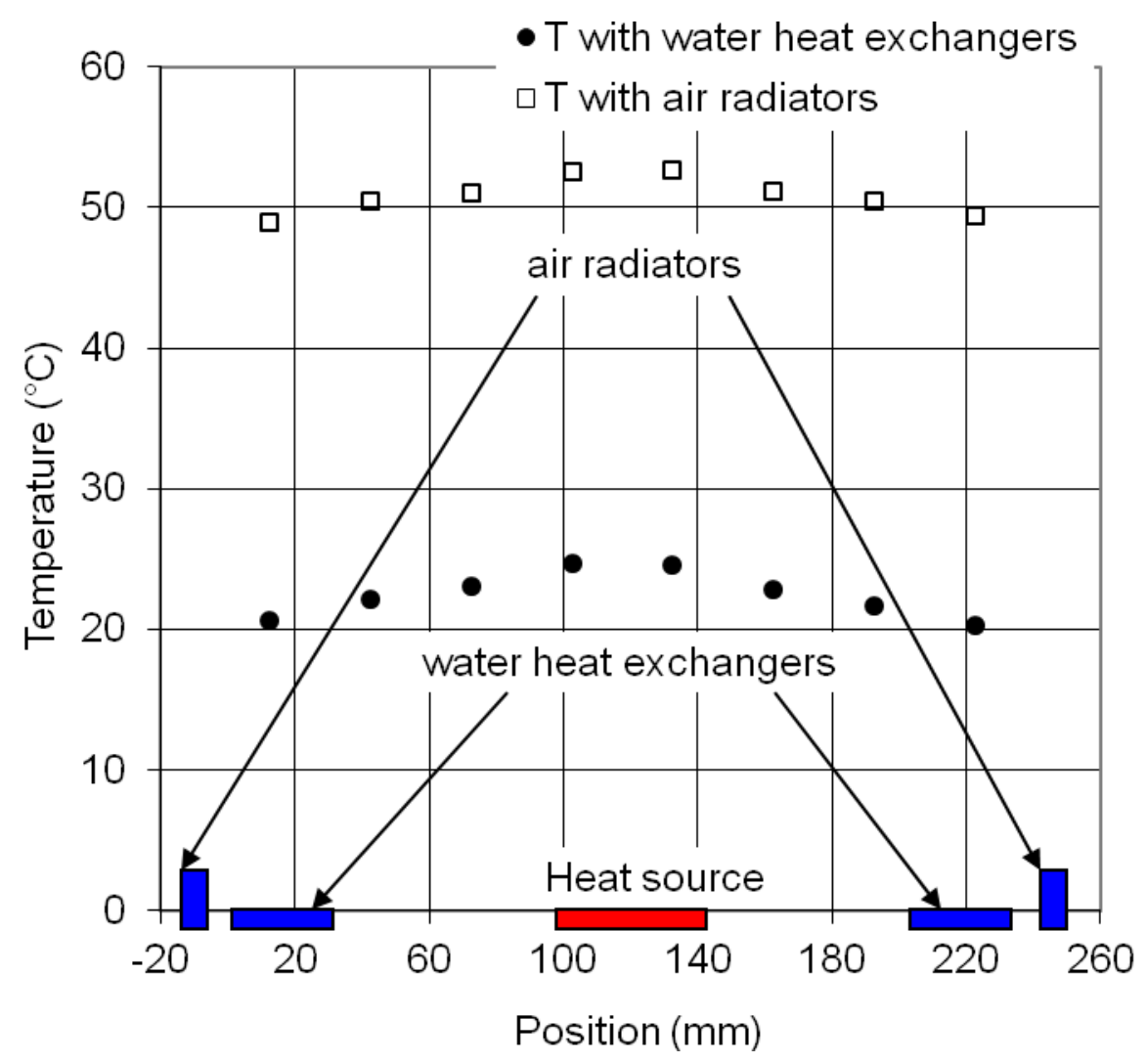

Figure 7: Influence of the heat sink nature on the characteristics of the heat pipe $n^{\circ} 1$ with two mesh screen layers $(\mathrm{Q}=15 \mathrm{~W})$

Figure 8 presents the maximal temperature difference between the heat source and the heat sinks in horizontal position vs. power. For the heat pipe $n^{\circ} 1$ with two mesh screen layers, linear characteristics are obtained until a threshold power of $82 \mathrm{~W}$ for which the thermal resistance is equal to $0.14 \mathrm{~K} / \mathrm{W}$. A copper plate with the same thermal performance would be more than $7 \mathrm{~mm}$ thick and an aluminium plate $(\lambda=160 \mathrm{~W} / \mathrm{mK})$ would be $18 \mathrm{~mm}$ thick, which shows the interest of using a FPHP to reduce the size and the weight of the thermal drain.

The maximum power is much higher than in the experiments presented in section 3.1.1. Indeed, for a given heat input, only half of the heat is transported to each end. Furthermore, the path followed by the liquid and the vapor inside the heat pipe $\mathrm{n}^{\circ} 1$ is much shorter. As a matter of fact, a shorter path reduces pressure drops and thus increases the heat transfer capacity. Similarly to section 3.1.1, a linear tendency is also observed after the first threshold, which shows that evaporation still occurs at the evaporator but there exists probably a narrow dryout between the mesh and the copper plate. 


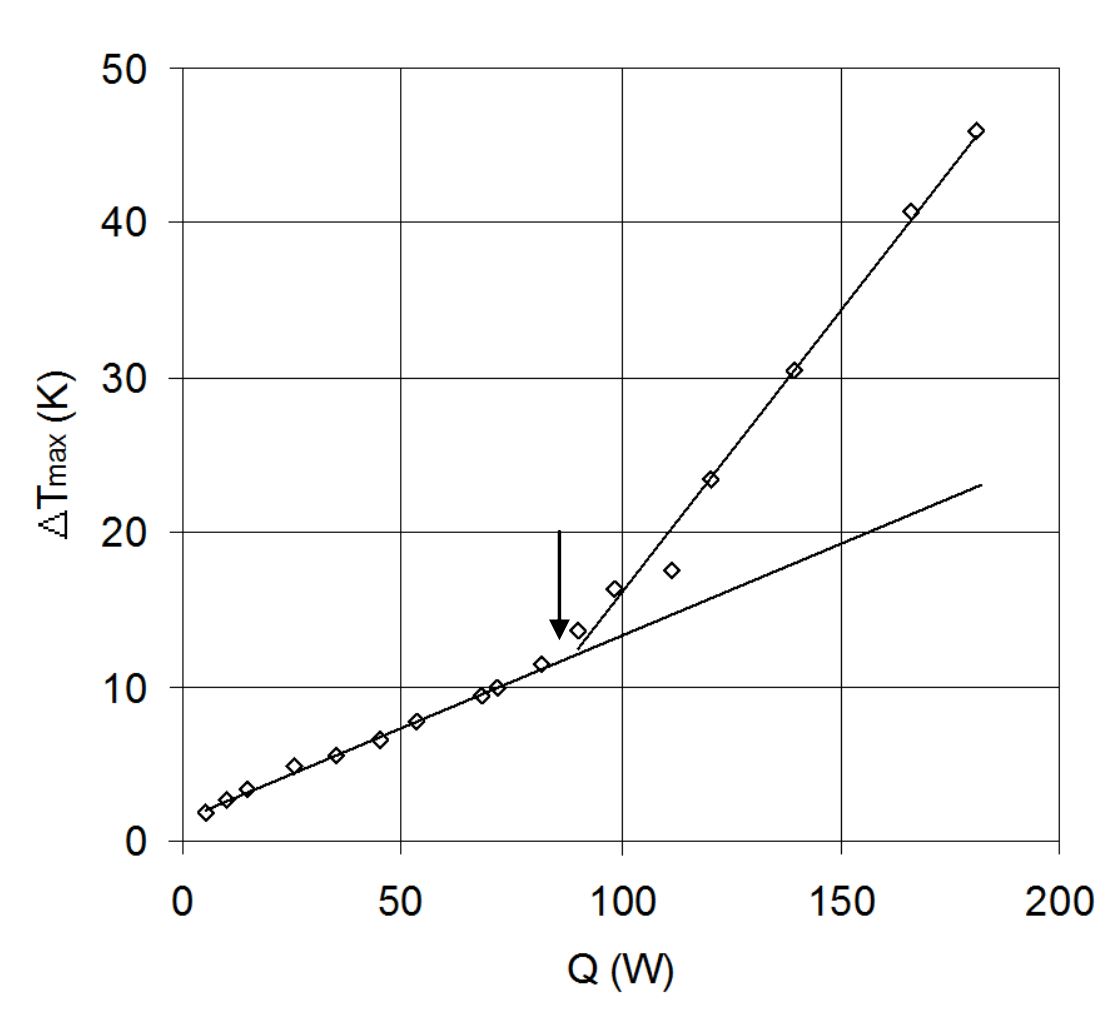

Figure 8: Maximal temperature difference vs. power; horizontal position (heat pipe $\mathrm{n}^{\circ} 1$ with two mesh screen layers)

Figure 9 presents temperature profiles along the heat pipe $\mathrm{n}^{\circ} 1$ for a power of $15 \mathrm{~W}$ and different orientations (i.e., in horizontal orientation, in vertical position, the FPHP laying on its longer edge and in vertical position, the FPHP laying on its shorter edge). Full line is the simulated temperature of a copper plate alone. The simulation includes $10 \%$ of heat losses from the system to the surroundings (i.e. the power is reduced by $10 \%$ ) to be closer to the experimental conditions. When the FPHP lays on its longer edge, results obtained in horizontal $(\bullet)$ or in vertical $(\Delta)$ positions, are really similar. 


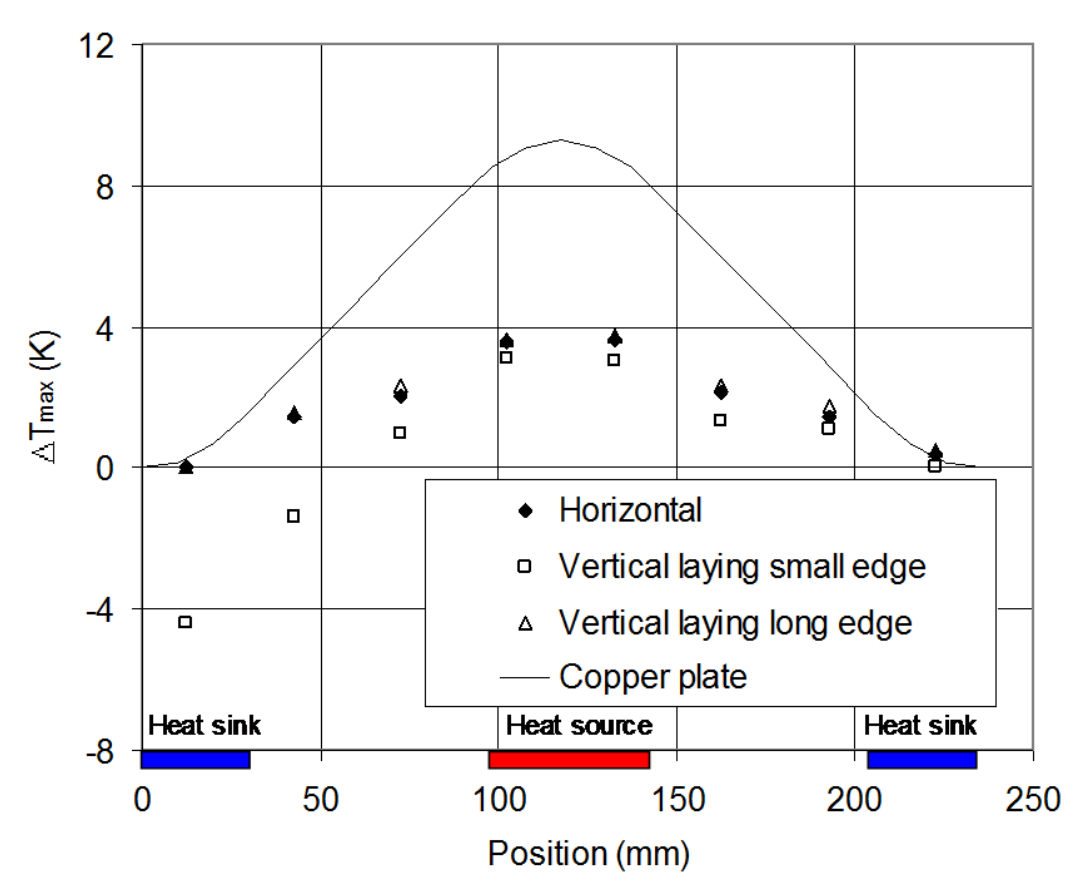

Figure 9: Temperature field for different tilt angles $\left(\mathrm{Q}=15 \mathrm{~W}\right.$, heat pipe $\mathrm{n}^{\circ} 1$ with two screen meshes)

Temperatures measured when the FPHP is vertical, laying on its shortest edge ( $\square$ ), are not symmetrical. They are similar to the temperatures measured in horizontal position on the top half of the FPHP while similar to that of a heat conduction temperature field in the copper plate on the other half. The top half is very favourable because gravity effects are superposed to capillary effects. On the contrary, on the bottom part of the FPHP, capillary pressure is not sufficient to overcome the hydrostatic pressure. Nevertheless, the heat sink located on the top of the FPHP is sufficient to cool the heat source. The minimum temperature considered for that experiment is the temperature at the condenser located on the top. This is the reason why temperatures decrease to negative values at the bottom of the pipe.

\subsection{FPHP made of grooves covered by two screen mesh layers}

In this part, we present results obtained with the heat pipe $n^{\circ} 2$. The capillary structure is made of 109 grooves covered by 2 screen mesh layers. The FPHP is filled with methanol. Excellent thermal performance was obtained with the same FPHP without screen mesh in horizontal position, but the FPHP was not able to work in vertical unfavourable position [1]. The aim of these new experiments is to check the ability of a combination grooves and meshes to work in tilted position.

Figure 10 presents temperature fields measured in horizontal orientation. The FPHP has been tested by increasing gradually the power from $\mathrm{Q}=1.9 \mathrm{~W}$ to $\mathrm{Q}=72.8 \mathrm{~W}$. The thermal resistance decreases 
slowly from $0.2 \mathrm{~K} / \mathrm{W}$ to $0.04 \mathrm{~K} / \mathrm{W}$, when the power increases, until a threshold value of $70 \mathrm{~W}$. Beyond this value, a sudden dryout occurs on the whole capillary structure and the thermal resistance reaches a value of $0.24 \mathrm{~K} / \mathrm{W}$.

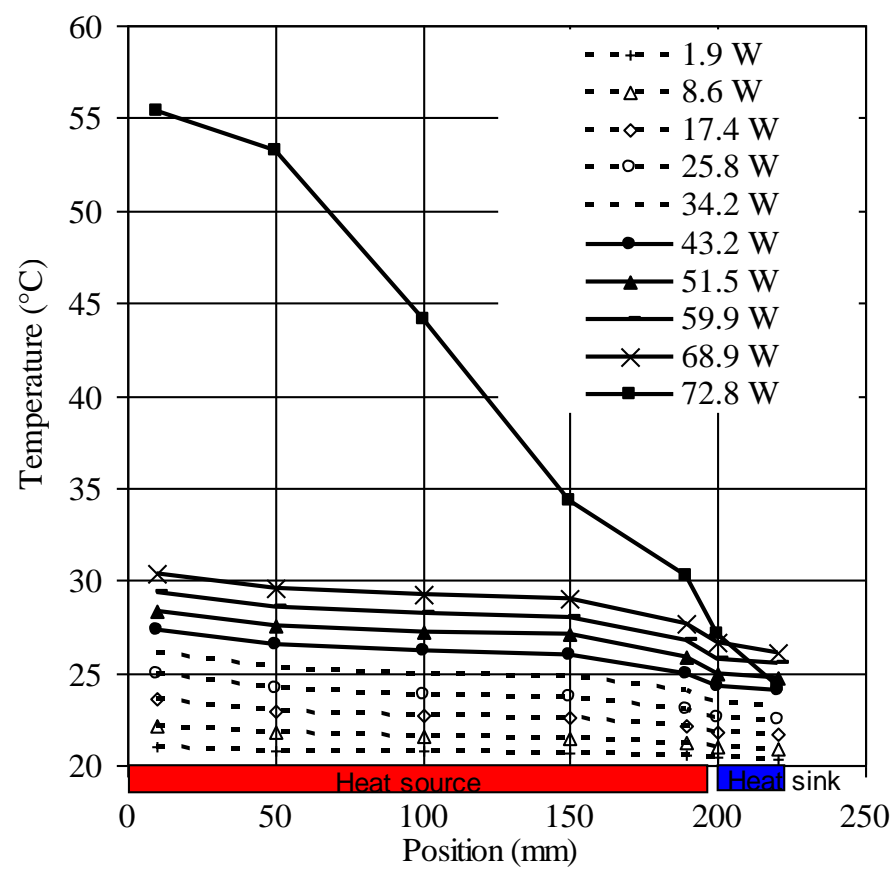

Figure 10: Temperature field along the heat pipe $n^{\circ} 2$ in horizontal position

These results must be compared to the experimental results obtained with the same FPHP without the screen meshes, presented in a previous paper [1]. For a power of $51.3 \mathrm{~W}$, the thermal resistance was equal to $0.023 \mathrm{~K} / \mathrm{W}$. In the present experiment it is equal to $0.045 \mathrm{~K} / \mathrm{W}$ for $\mathrm{Q}=51.5 \mathrm{~W}$. The difference is due to the additional thermal resistance of the 2 screen mesh layers. The second parameter that has to be compared is the capillary limit, which was higher than $150 \mathrm{~W}$ without the screen meshes. Furthermore, the dryout was not observed on the whole surface of the FPHP, but only at its extremity. In the present experiment, beyond $70 \mathrm{~W}$, the entire surface is dry. This comparison shows that the limit reached in the present experiment is not a capillary limit but rather a boiling limit. This catastrophic dryout is probably due to the rapid expansion of bubbles, which grow between the screen mesh layer and the grooves, rather than outside of it, because of the capillary pressure barrier imposed by the meshes. As a result, bubble growth pushes away the liquid from the grooves. As the screen mesh layers are not able to drain the liquid on the entire surface, the capillary structure suddenly dries out after the boiling incipience. 
As soon as the capillary structure is dry, a power decrease does not allow rewetting it. A strong hysteresis is observed. Furthermore, if the power does not increase progressively like in figure 10, but abruptly, dryout occurs for a much lower power than the threshold observed in figure 10.

Figure 11 presents temperature profiles obtained along the FPHP inclined by $15^{\circ}$ from the horizontal position, the heat source being above the heat sink. The FPHP has been tested by increasing gradually the power from $\mathrm{Q}=2.0 \mathrm{~W}$ to $\mathrm{Q}=41.0 \mathrm{~W}$. The thermal resistance decreases slowly from $0.2 \mathrm{~K} / \mathrm{W}$ to $0.05 \mathrm{~K} / \mathrm{W}$ until a threshold value of $40 \mathrm{~W}$. Similarly to the horizontal position, beyond this power, a sudden dryout occurs on the whole capillary structure and the thermal resistance reaches a value of $0.24 \mathrm{~K} / \mathrm{W}$.

All these observations show a strong limitation of the association meshes and grooves. In horizontal position, the maximum heat flux is considerably reduced compared to that obtained with a simple grooved surface. This association allows using FPHP in tilted position, but nucleate boiling in narrow space occurs for rather small heat fluxes $\left(\sim 0.2 \mathrm{~W} / \mathrm{cm}^{2}\right)$. All these observations shall be investigated more accurately to understand the physical mechanisms responsible for this behaviour.

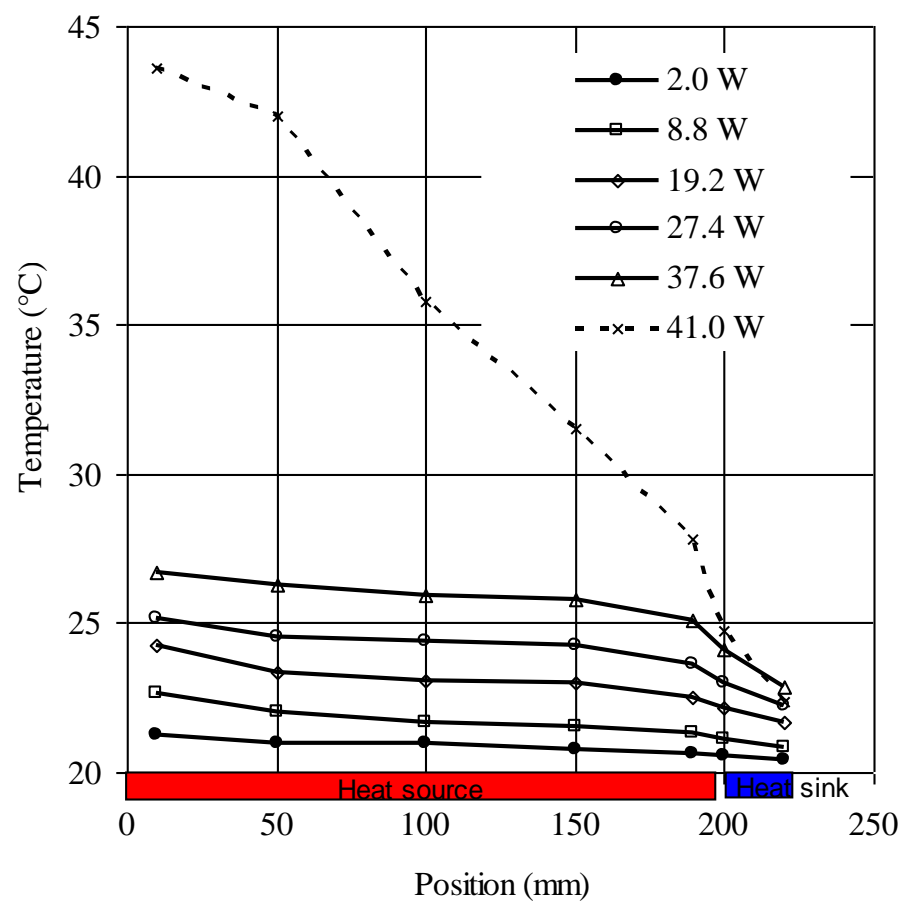

Figure 11: Temperature profile along the heat pipe $n^{\circ} 2$ inclined by $15^{\circ}$ from the horizontal

\section{Conclusion}


Experimental data obtained with two different flat plate heat pipes of similar dimensions were presented. The assembly of the first FPHP is very simple and show good thermal performance for the proposed application. FPHP thermal performance does not depend on the nature of the heat sinks: experimental results are similar using air radiators as cold sources rather than water heat exchangers. Good thermal performance is also observed in various tilted positions when two heat sinks are used at each extremity of the FPHP. In horizontal position, a clear threshold is observed with one mesh when the capillary limit is reached whereas it is less explicit with 2 meshes. The results obtained with the association of grooves and meshes are disappointing. Indeed, even though this association allows working in unfavourable tilted position, which is not possible with grooved heat pipes, a strong nucleate boiling limitation is observed for rather small heat fluxes. These observations shall be investigated more accurately to understand the physical mechanisms responsible for this behaviour.

\section{References}

[1] Rullière, R., Lefèvre, F., Lallemand, M., Prediction of the maximum heat transfer capability of two-phase heat spreaders - Experimental validation, Int. J. Heat Mass Transfer, 50, pp. 1255-1262, 2007.

[2] Lefèvre, F., Rullière, R., Pandraud, G., Lallemand, M., Prediction of the temperature field in flat plate heat pipes with micro-grooves - Experimental validation, Int. J. Heat Mass Transfer, 51, pp. 4083-4094, 2008.

[3] Longtin, J. P., Badran, B., Gerner, F. M., A one-dimensional model of a micro heat pipe during steady-state operation, J. Heat Transfer, 116, pp. 709-715, 1994.

[4] Launay, S., Sartre, V., Mantelli, M. B. H., de Paiva, K. V., Lallemand, M., Investigation of a wire plate micro heat pipe array, Int. J. Therm. Sci., 43, pp. 499-507, 2003.

[5] Wang, Y. X., and Peterson, G. P., Analysis of wire-bonded micro heat pipe arrays, J. Thermophysics Heat Transfer, 16, pp. 346-355, 2002.

[6] Sonan, R., Harmand, S., Pellé, J., Léger, D., Fakès, M., Transient thermal and hydrodynamic model of flat heat pipe for the cooling of automotive electronic components, Int. J. Heat Mass Transfer, 51, pp. 6006-6017, 2008

[7] Harmand, S., Sonan, Fakès, M., Hassan, H., Transient cooling of electronic components by flat heat pipes, Applied Thermal Engineering, 31, p.p. 1877-1885, 2011.

[8] Lefevre, F., Rullière, R., Lips, S., Bonjour, J., Confocal microscopy applied to capillary film measurements in a radial flat plate heat pipe made of silicon, J. Heat Transfer, 132, 031502 pp.1-6, 2010.

[9] Lips, S., Lefèvre, F., Bonjour, J., Combined effects of the filling ratio and the vapour space thickness on the performance of a flat plate heat pipe, Int. J. Heat Mass Transfer, 53, pp. 694-702, 2010.

[10] Lips S., Bonjour J., Lefèvre F., investigation of evaporation and condensation processes specific to grooved flat heat pipes, Frontiers in Heat Pipes, 1, pp. 112901, 2010.

[11] Lips, S., Lefèvre, F., Bonjour, J., Nucleate boiling in a flat grooved heat pipe, International Journal of Thermal Sciences, 48, pp. 1273-1278, 2009.

[12] Lips, S., Lefèvre, F., Bonjour, J., Physical mechanisms involved in grooved flat heat pipes: experimental and numerical analyses, Int. J. Therm. Sci., 50, pp. 1243-1252, 2011. 
[13] Kempers, R., Ewing, D., Ching, C.Y., Effect of number of mesh layers and fluid loading on the performance of screen mesh wicked heat pipes, Applied Thermal Engineering, 26, pp. 589-595, 2006.

[14] Kempers, R., Robinson, A.J., Ewing, D., Ching, C.Y., Characterization of evaporator and condenser thermal resistances of a screen mesh wicked heat pipe, Int. J. Heat Mass Transfer, 51, pp. 6039-6046, 2008.

[15] Wong, S.C., Kao, Y.H., Visualization and performance measurement of operating meshwicked heat pipes, Int. J. Heat Mass Transfer, 51, pp. 4249-4259, 2008.

[16] Wong, S.C., Liou, J.H., Chang, C.W., Evaporation resistance measurement with visualisation for sintered copper powder evaporator in operating flate plate heat pipes, Int. J. Heat Mass Transfer, 53, pp. 3792-3798, 2010.

[17] Liou, J.H., Chang, C.W., Chao, C., Wong, S.C., Visualisation and thermal resistance measurement for the sintered mesh-wick evaporator in operating flat plate heat pipes, Int. J. Heat Mass Transfer, 53, pp. 1498-1506, 2010.

[18] Li, C., Peterson, G.P., Evaporation/Boiling in thin capillary wicks (I) - Wick thickness effects, J. Heat Transfer, 128, pp. 1312-1319, 2006.

[19] Li, C., Peterson, G.P., Evaporation/Boiling in thin capillary wicks (II) - Effects of volumetric porosity and mesh size, J. Heat Transfer, 128, pp. 1320-1328, 2006.

[20] Li, C., Peterson, G.P., The effective thermal conductivity of wire screen, Int. J. Heat Mass Transfer, 49, pp. 4095-4105, 2006.

[21] Do, K.H., Ha, H. J., Jang, S.P., Thermal resistance of screen mesh wick heat pipes using the water-based $\mathrm{Al}_{2} \mathrm{O}_{3}$ nanofluids, Int. J. Heat Mass Transfer, 53, pp. 5888-5894, 2010.

[22] Stutz, B., Morceli, C.H.S., Da Silva, M.F., Cioulachtjian, S. and Bonjour, J., Influence of nanoparticle surface coating on pool boiling, Experimental thermal and fluid science, 35, pp. 12391249, 2011.

[23] Rosenfeld J. H., Gernert N. J., Sarraf, D. B., Wollen P., Surina F., Fale J., Flexible heat pipe, United States Patent 6,446,706, 2002. 